\title{
THE ADDICT AS VICTIM: PRODUCING THE ‘PROBLEM’ OF ADDICTION IN AUSTRALIAN VICTIMS OF CRIME COMPENSATION LAWS
}

\section{KEYWORDS}

Addiction, law, crimes compensation, Australia, problematisation, Carol Bacchi

\begin{abstract}
Much academic scholarship has explored drug use and 'addiction' in the criminal justice system. This paper explores what happens when 'addicts' are victims, through an analysis of victims of crime compensation case law within the state of Victoria, Australia. We argue that the law enacts a set of unexamined assumptions about the 'problem' of addiction, including the assumption that it is incompatible to be both addict and victim. However, courts reconcile this ‘dilemma' by explaining addiction as an 'effect' of trauma, violence or abuse, a seemingly sympathetic rendering of addiction. Although this appears to represent a less stigmatising approach than found in the criminal law, we argue that these processes actually produce new challenges for people who use drugs and 'addicts', and that these may be counter to the stated aims and objectives of crimes compensation law. We argue that even legal systems with an explicitly remedial rationale have the potential to generate harms, creating those who use drugs and 'addicts' as pathological in certain ways and thereby undermining their claims to citizenship. Our analysis is underpinned by a critical approach to the constitution of social problems based on the work of Carol Bacchi. Although the focus is on Australian law, the arguments we develop in this paper are likely to resonate beyond the specific jurisdiction reviewed here, and raise questions about the mutually interdependent role of law and policy in compounding the stigmatisation and marginalisation of people who use drugs and drug 'addicts'.
\end{abstract}




\section{INTRODUCTION}

People whose drug consumption is understood to be problematic feature prominently in the criminal justice system as offenders - charged with crimes relating to the use, possession and/or trafficking of drugs, public conduct offences while under the influence of alcohol or other drugs, or other criminal offences (such as robbery and burglary) that are sometimes understood to be linked in important ways to their drug use or 'addiction'. A large body of academic scholarship has explored the intersections between problematic substance use or ‘addiction' and the criminal justice system. This work has examined topics including, for example, the nature of the relationship between 'addiction', drugs, alcohol and criminal offending (Stevens 2007; Hammersley 2008; Seddon 2000), the development and practices of specialist drug courts (Murphy 2012, 2011; Vrecko 2009; Burns and Peyrot 2003) and the expansion and application of alternative models of sentencing and rehabilitation, such as those associated with therapeutic jurisprudence models (Gowan and Whetstone 2012; Fitzgerald 2008; Clancey and Howard 2006). Within sociology and criminology researchers have also examined understandings and experiences of the 'addict' in criminal justice systems. This work looks at the way individual 'addicts' are configured in the criminal justice system in general, and mandatory treatment regimens in particular (Lyons 2013; Seddon 2011; Vrecko 2009) and how they experience the court system and treatment. Although it seems an obvious point, people who are characterised as experiencing either problematic substance use or an 'addiction' also appear in criminal justice systems in other capacities, including as the victims of crime. They may be the victims of crime where the criminal act is related to their drug consumption or 'addiction' (where violence occurs as part of a drug deal, for instance), but also where there is no obvious link with their consumption of drugs (where they are the victims of a random assault, rape or robbery). In this respect, individuals 
ordinarily understood as transgressive citizens on the 'wrong side of the law' may find themselves in an unusual position, seeking redress from the state as the victims of crime.

The phenomenon of the addict-as-victim raises a number of important questions. How, for instance, does the law assess the significance, if any, of a victim of violent crime also being a drug user and/or addict? How, for what reasons and in what ways might drug 'addiction' be considered as relevant to one’s status as victim? Does drug use and/or addiction impact in any way on conceptualisations of victims of crime as innocent and/or deserving of care and support, whether from the community or the state? How does the criminal justice system understand the subject position of the 'addict-as-victim'? Where these two subject positions (of 'addict' and 'victim') are understood to be at odds, how does the criminal justice system reconcile them, if at all? And what are the implications of these judicial formulations and processes for contemporary understandings of both addiction and victimhood? Similar questions have been asked before, especially by researchers with an interest in victimology. We already know, for example, that questions about the 'character' and 'conduct' of victims figure centrally in the criminal justice system. Scrutiny of a victim's past experiences, past conduct and present conduct often occurs as part of prosecution deliberations about whether or not to lay charges against an offender - as in, for instance, rape cases where the victim consumed alcohol or illicit drugs before an assault (Beichner and Spohn 2012). Questions about the conduct and character of the victim also emerge in criminal trials themselves, where narratives about the attitude, attributes and conduct of the victim are raised, whether to advance doubt about the offender's guilt, as a partial defence to crimes such as murder, or in mitigation of sentence (Tyson 2013, Grubb and Turner 2012). This paper is not concerned with how 'addiction' figures in either of these senses, however. Instead, it is concerned with the more specific question of how drug use and/or 'addiction' are conceptualised when judges are enjoined to make decisions about compensation for 
people adjudged to be victims of crime. There has been little critical work which explores how the law pertaining to victims of crime compensation understands drug use and/or ‘addiction’ in such circumstances, nor how judicial figures shape awards of compensation to 'addicted' victims.

This paper explores these issues through an analysis of victims of crime compensation case law within the state of Victoria, Australia. In what follows, we examine how courts assess the relevance of addiction and drug use to victims of crime compensation applications, as well as how they perform victimhood, addiction and the agency of addicts. We argue, first, that drug use and addiction are constituted as both relevant to crimes compensation applications and as potential obstacles to the award of such. In producing drug use and addiction as relevant problems, courts generate questions about addiction (its 'nature', 'causes' and 'effects') for which solutions must be found. In this sense, crimes compensation law emerges as a key site in the production of meanings around drug use and addiction and for the construction of addiction as a significant social problem. The paper can also be situated within a longer tradition of critical legal scholarship exploring the law's capacity to reproduce and further entrench inequality and stigma, such as that for victims of domestic violence and rape (e.g. MacKinnon 2005, 1987; Koss 2000). We argue that crimes compensation ultimately produces and reproduces a set of problematic assumptions about addiction, which include the possibility that there is something inherently incompatible about being both an addict and a victim. However, courts frequently reconcile these seemingly incompatible subject positions by explaining addiction as an 'effect' of trauma, violence or abuse, thus rendering sympathetic the 'addict' in the eyes of the state. Although this appears, on the face of it, to represent a less stigmatising and marginalising approach to addiction than found in criminal law, we argue that these processes of reconciliation actually produce new challenges for people who use drugs and addiction, and that these may be counter to the 
stated aims and objectives of crimes compensation law. In this respect, our analysis offers a critical challenge to the 'realist' approach to drugs and social problems, which suggests that drugs have particular (negative) effects, and that the origins of drug-related harms lie within the chemical properties of drugs themselves (see, for example, Duff 2013; Demant 2013; Dwyer and Moore 2013; Fraser and Moore 2011; Keane 2002). Instead, we suggest that legal systems have the potential to generate their own harms, which includes legal realms with an explicitly remedial rationale. We also argue that crimes compensation courts produce a contradictory set of messages about responsibility for the 'problem’ of addiction, insofar as addicts are positioned as simultaneously exempt from responsibility and accountable for their actions. Our research shows that a similar process is in operation even among legislative schemes with an explicitly remedial rationale: an issue that is rarely acknowledged and that researchers, governments and legal practitioners need to better understand. Our study raises serious questions about how individuals navigate these ostensibly incompatible messages, and the rights and responsibilities of people who consume drugs, as a result. Our analysis is underpinned by a critical approach to the constitution of social problems and in the next section we introduce key aspects of this method. Following this, we provide an overview of crimes compensation schemes in Australia and Victoria, before moving to an analysis of specific cases within which 'addiction' appears. We argue that although the focus is on Australian law and legal practice, the arguments we develop in this paper are likely to resonate well beyond the specific jurisdiction under review here, especially insofar as they demonstrate the law's capacity to constitute addiction and drug consumption as a particular kind of problem, and insofar as the law enacts a set of contradictory messages about the agency and volition of addicts, and the ontology of addiction.

\section{THE CONSTITUTION OF SOCIAL PROBLEMS}


Our analysis is framed by Carol Bacchi’s (2009) recent methodological work on analysing policy. Bacchi’s approach is based on Michel Foucault's work, in particular his insights on ‘problematisation’ and his interest in ‘thinking problematically’ (1977, 185-186). According to Bacchi (2012) the term problematisation has two meanings. First, quoting Deacon (2000, 127), she argues that problematisation refers to the process of examining how a given issue is 'questioned, analysed, classified and regulated' at particular times and under particular conditions. Second, she says, problematisation also means, as Foucault puts it $(1985,115)$, '[h]ow and why certain things (behaviour, phenomena, processes) become a problem' and how they are, in her own words, 'shaped as particular objects for thought' $(2012,1)$. This way of approaching problems has profound ontological and epistemological implications. Bacchi (2012) goes on to explain these implications, again quoting Foucault $(1988,257)$ : Problematisation doesn’t mean the representation of a pre-existing object, nor the creation through discourse of an object that doesn't exist. It is a set of discursive and non-discursive practices that makes something enter into the play of the true and the false and constitutes it as an object for thought (whether under the form of moral reflection, scientific knowledge, political analysis, etc).

While Foucault focused on what he called 'crisis' points (such as sexuality, madness and so on), Bacchi expands the role of problematisation, in particular via her interest in policy. In her 2009 book Analysing policy: What's the problem represented to be? Bacchi argues that, policy does not simply ‘address' social problems. Instead, policies actually 'shape' them (2009: x). Particular policies identify certain phenomena as problems, and in doing so presuppose and imply certain ways of understanding these problems. The ways a policy understands and 'shapes' a certain problem can be read off the solutions it proposes and seeks to implement. This way of analysing policy has been used in a number of recent articles exploring drug issues (Moore and Fraser 2013; Lancaster and Ritter 2013; Lancaster, 
Hughes, Chalmers and Ritter 2012), and has formed the basis for a new subfield of drug policy research work in Australia.

It is of course possible to read many discursive practices, not only policy, in the way Bacchi proposes. Just as policy is seen to 'address' the problems it actually helps constitute, so too, for instance, does the law. A commonplace explanation for the law is that it has evolved to deal with the various tensions, conflicts and problems that arise in conduct within society. Foucault's (and Bacchi’s) approach suggests instead that the law creates particular categories of transgression (or 'problems' of transgression) at particular times depending upon contemporary political and other forces, both explicit and implicit. It acts on these using particular strategies. Drug use is an especially salient example of this process in that drugs vary over time and place, in terms of their definition, legal status and the kinds of prohibitions and punishments attached to their use. Instead of naturalising the law as a set of necessary responses to crimes or transgressions all agree must not go unpunished or unaddressed, therefore, we can see the law as reflecting, and in turn re-enacting, the (always changing) values of a given society. If we read legal discourse as does Bacchi on policy, we can expose its role in formulating social problems rather than simply addressing them. Doing this allows us to create space to critically assess these formulations for their assumptions and oversights, and for the ways in which they might reinforce or exacerbate social inequalities or exclusions as much as ameliorate them. As well as this, legal formulations of addiction have a significant relationship with policy, insofar as policies around drug use and service provision often take up, rely upon or reproduce prior legal outcomes in relation to drug use. This most often occurs via the criminal law (especially where convictions for drug offences are sustained, with implications for other legal rights and responsibilities, and so on). The key point here is that legal processes and outcomes invariably fold back into other policy realms, potentially compounding the stigmatisation and marginalisation of people who use drugs. 
This raises important questions for policymakers and governments, and is a matter we will return to in our conclusion.

Bacchi’s method poses six questions, accompanied by an undertaking to apply the questions to one's own policy proposals. This analytic strategy, which she calls 'What's the Problem Represented to be?' (or WPR approach), has been modified below to fit the field of analysis relevant to this article:

1. What is the problem of addiction represented to be in specific case law?

2. What presuppositions or assumptions underlie the representation of this 'problem'?

3. How has this representation of the 'problem' come about?

4. What is left unproblematic in this problem representation? Where are the silences?

5. What effects are produced by this representation of the problem?

6. How/where has this representation of the 'problem' been produced, disseminated and defended? How could it be questioned, disrupted and replaced?

Importantly, term 'effects' has a specific meaning here. In Bacchi’s work, 'effects' do not refer to 'the standard policy approach to evaluation with a focus on "outcomes”' (2009: 15), but to three 'interconnected and overlapping’ effects. These are: discursive effects, such as the limits imposed on thinking when a 'problem' is framed in a certain way; subjectification effects, where practices make certain subject positions available, affecting how we think about and understand ourselves as subjects; and lived effects, or the material impact of problem representations. In this paper, we are specifically interested in the subjectification effects of crimes compensation law, although we briefly touch upon some of the discursive and lived effects of these discursive practices. In this article we begin our discussion with question 6, noting that crimes compensation law is a largely neglected arena in which drug addiction is constituted as a particular kind or set of social problems, and disseminated as 
such through the actions of legal representatives and processes. In the discussion that follows our analysis emphasises questions 1, 2, 4 and 5, looking at how addiction is being framed, what assumptions inform these framings, what silences are also made in this process and what kinds of effects follow from these framings and silences. The article closes in turning to question 7, which asks us how these problematisations we identify could be interrupted and reframed to produce more equitable results.

\section{VICTIMS OF CRIME COMPENSATION: A BRIEF INTRODUCTION}

Victims of crime compensation legislation first came into being in Australia during the 1960s. As Ian Freckleton (2004: 31) explains:

The payment of financial compensation for the non-pecuniary effects of crime, such as the pain and suffering engendered by criminal acts of violence, is a phenomenon of comparatively recent experience. It accompanied the dawning of awareness of the impact of criminal offences of violence upon victims during the 1960s and into the 1970s.

Although approaches vary between jurisdictions (Freckleton 2004), victims of crime compensation is generally regarded as 'remedial' or 'beneficial' legislation, insofar as the intended purpose is usually to support, rehabilitate or otherwise benefit victims of crime. Putting to one side questions about the extent to which victims of crime legislation achieves these aims, there are important links between such laws and principles of restorative justice and therapeutic jurisprudence. So, for example:

Proponents of therapeutic jurisprudence ... have identified a potential for healing in the victim being compensated by the person who has been the author of their misfortune. (Freckleton 2004: 58) 
Freckleton (2004: 58) also argues that the significance of crimes compensation is that it can be a 'therapeutically symbolic gesture of collegiality and concern' by the community and the state, as well as potentially 'cathartic' for victims. In this respect, victims of crime compensation is founded upon an assumption that literal and symbolic articulations of emotion have the potential to produce certain emotional 'effects' with regards to subjects and that such effects are predominantly positive. As Sara Ahmed (2004) has argued, however, articulations of emotion may sometimes work in problematic ways, by, for example, generating distinctions between people, and in so doing 'enacting' different classes of subject. As well, these articulations work to produce some groups of people as more - or less - deserving than others. This is a point we have explored in our earlier work on hepatitis C (XXXX 2010) and is worth bearing in mind as we consider the unintended and potentially negative consequences of crimes compensation. This is especially pertinent as we consider how legal processes work to categorise some individuals as deserving victims for the purposes of the Act, while others may be excluded from eligibility, care and support.

All states and territories of Australia, where this research was undertaken, have some form of crimes compensation legislation. Within Victoria, where this study is based, the principal piece of legislation is the Victims of Crime Assistance Act (VOCAA) which was enacted by a conservative government in 1996. ${ }^{\mathrm{i}}$ The stated purpose of the Act is to assist victims of crime (as per section 1 (1) of the Act), and there are three main objectives, as per section 1 (2) of the Act.:

(a) to assist victims of crime to recover from the crime by paying them financial assistance for expenses incurred, or reasonably likely to be incurred, by them as a direct result of the crime; and

(b) to pay certain victims of crime financial assistance (including special financial assistance) as a symbolic expression by the State of the community's sympathy and 
condolence for, and recognition of, significant adverse effects experienced or suffered by them as victims of crime; and

(c) to allow victims of crime to have recourse to financial assistance under this Act where compensation for the injury cannot be obtained from the offender or other sources.

The Act draws a distinction between 'primary' victims (the person who sustains the injury or dies as a result of an act of violence) and others, such as relatives and 'secondary' victims who witness an act of violence. The legislation allows for applications to be made by all categories of victim, although there are slightly different criteria for eligibility depending on the category.

For the purposes of the analysis that we want to undertake here it is not necessary to provide a detailed explanation of how applications under the Act are to be made or the various supports available. For reasons that will become clearer, however, we want to draw out four relevant aspects of the Act that bear upon the argument we make. These are:

1. That the legislation provides for compensation only where the person is a victim of an 'act of violence', the meaning of which appears in the Act. It is important to note that it is not necessary for the alleged offender to have been identified or identifiable, nor to have been charged or convicted in order for an award of compensation to be made. In criminal cases, a person must be found guilty to the standard of 'beyond reasonable doubt'. Under the VOCAA, the standard is lower, so that the tribunal only needs to be satisfied on the balance of probabilities that an act of violence has occurred;

2. A person must make an application for compensation within two years of the occurrence of the act of violence. If an application has not been made within this time, the tribunal is required to strike the application out unless there are circumstances to warrant the application being allowed to proceed. Section 29 of the Act requires the tribunal to consider factors such as the age of the applicant at the time of the offence, 
whether there was a power imbalance between the victim and the alleged offender, any intellectual disability or mental illness experienced by the applicant, any physical or psychological effect of the act of violence on the victim, and 'all other circumstances’ it considers relevant. So, for example, if a person was sexually assaulted by a parent as a child and did not report the offences or bring the application until they reached adulthood, the tribunal may allow the application to proceed on the basis that the delay is justified and justifiable;

3. The tribunal must take into consideration a number of factors, pursuant to section 54 of the Act, when deciding whether or not to make an award of compensation. These include - crucially - the 'character, behaviour (including past criminal activity and the number and nature of any findings of guilt or convictions) or attitude of the applicant at any time, whether before, during or after the commission of the act of violence'. If the application is made in respect of a person who has died as a result of an act of violence, the tribunal must take into consideration the character or behaviour (including past criminal activity and the number and nature of any findings of guilt or convictions) of the deceased victim. This provision differs from that in some other Australian jurisdictions insofar as it is mandatory - rather than discretionary - for the court to consider the applicant's character, behaviour or attitude; and

4. The tribunal has capacity, under sections 8 and $8 \mathrm{~A}$ of the Act, to make an award of compensation to the victim. This may include a financial lump sum, as well as an award for counselling services, loss of earnings, clothing damaged during an act of violence, or 'medical expenses actually and reasonably incurred, or reasonably likely to be incurred, by the primary victim as a direct result of the act of violence'.

The question of substance use, abuse, dependence or addiction is not specifically dealt with anywhere in the Act. In spite of this, as we have already noted, addiction figures in a number 
of reported decisions. In what follows, we will examine, first, how addiction surfaces in the case law - or, to put it slightly differently, how addiction surfaces as a problem and a problem of relevance to crimes compensation applications. Having constituted addiction as a matter of relevant concern, we consider what questions courts pose for themselves to consider in relation to the 'problem' of addiction. Finally, we analyse how decision-makers resolve the difficulties that are produced through the course of deliberations, and what these resolutions mean for the health and wellbeing of people who are constituted as addicts in the process. ${ }^{\text {ii }}$

\section{ADDICTION IN VICTORIAN CRIMES COMPENSATION}

Table 1 contains an overview of reported crimes compensation cases from the Victorian jurisdiction ${ }^{\mathrm{iii}}$ where addiction appeared. These cases were located through the Australasian Legal Information Institute (AUSTLII) search engine, which is the principal legal search engine in Australia. We found that there were 10 reported cases where 'addiction' or 'dependence' had appeared in the written reasons of judgment, three of which were excluded for the purposes of the present analysis on the basis that the question of addiction was dealt with only briefly in the case (a reference to the applicant being an 'addict' might have been made, for example, in the body of the judgment, but its relevance to the application was not advanced any further) ${ }^{\mathrm{iv}}$.

(Table 1 goes here)

\section{WHY IS ADDICTION RELEVANT?}

Addiction emerges in the case law in three main respects. These are:

1. Where an application for compensation has been made out of time (so that, pursuant to section 29 of the Act, the court must consider whether there are 
circumstances that justify the application proceeding despite the delay, and substance use or 'abuse' is considered to be of possible relevance);

2. Where, under section 54 of the Act, the court is required to consider the applicant's character, behaviour or attitude; and

3. Where the applicant is claiming medical expenses under section 8 of the Act, and those medical expenses include treatment that is potentially related to drug use and the act of violence.

Addiction figures most often and most explicitly in relation to the second and third questions, and it is these that we will focus on in the remainder of this paper. ${ }^{\mathrm{v}}$ In five of the seven cases, drug use and addiction were understood to be somehow relevant to the question of whether or not the applicant was deserving of compensation. In many respects this might be said to reflect the very broad nature of section 54 (in that it permits the court to consider any aspect of the applicant's life to date) along with the fact that it is mandatory to attend to questions about the applicant's character. Importantly, however, section 54 offers no guidance as to what might be a relevant consideration, what weight should be given to relevant considerations in deciding whether or not to make an award, and how those considerations impact on decisions about the kind or size of award to make. The upshot of this is that judges have considerable scope for determining what is both 'relevant' and 'problematic', notions that have the potential to be taken up in subsequent case law as self-evidently relevant and problematic (especially via the doctrine of precedent, which is a principle of law that requires judges to apply judicial reasoning from past cases to present cases with similar facts). It is telling, therefore, that drug use and 'addiction' were understood to be of note, and a potential obstacle to the provision of compensation in five of the seven cases, although the apparent relevance of drug use and addiction varied. 
The case of Hassell offers a useful - and fairly typical - example of how illicit drug use and/or addiction surface in relation to the 'character' provision. In the Hassell case, the applicant suffered serious injuries as a result of an assault at a factory in suburban Melbourne. The assault took place when Hassell travelled with his lodger and two acquaintances to collect money that was owing to one of them. Although Hassell did not know so at the time, the debt was drug-related, and when they arrived at the factory, all four of them were attacked. Hassell was unarmed and suffered serious facial injuries after being attacked with a machete. The tribunal dismissed his application at first instance 'because of his prior criminal offending, and because the assault occurred in circumstances where he was assisting a friend who was clearly, on any view, involved in the drug industry'. The reported judgment was from the appeals court, who agreed to hear Hassell's application for review on this specific question. Under a section dedicated to 'the applicant's criminal history’, the appeals court raised the question of his heroin addiction, noting:

The applicant concedes that he was previously addicted to heroin. He accepts responsibility for committing the criminal offences. At the time he says he made some poor choices about the company he kept who in the main also had drug issues. Here, it is unclear precisely how addiction is being problematised by the court, whether Hassell's illicit drug use is considered relevant as an instance of past 'criminal activity' (something that is specifically referred to in section 54), whether it is thought to be relevant for other reasons, whether his addiction is a discrete instance of concern, or whether his drug use is relevant on all three fronts. Whatever the case, the court has clearly problematised his drug use and addiction in association with his criminal history under the character provision, producing it a potential obstacle to the provision of compensation. The possibility that being a heroin addict might be incompatible with being an eligible victim is raised. Strictly speaking, the specific legal question before the court is whether or not the application can 
succeed in spite of Hassell's drug use, criminal history and addiction. In order to answer this, however, the court produces a set of sub-questions for itself, each of which is implicit in both the short passage above and the balance of the written judgment. These are: is it possible to be both a drug user/addict and a victim? If so, how might we reconcile these positions? What are the reasons for the applicant's criminal activity, past drug use and addiction? How does he account for those aspects of his past? And is there evidence of him being repentant, remorseful and reformed?

For reasons that will shortly become apparent, very similar questions are posed when courts consider applications for medical expenses under section 8 of the Act. The case of $J M$ $v$ VOCAT concerned an application for compensation by a victim of a childhood sexual assault. In JM's case the specific issue to be determined was whether he should receive compensation for methadone treatment related to his heroin addiction, the costs of dental work pertaining to the neglect of his teeth during the period of his heroin use, and treatment for hepatitis $C$ that the applicant developed through his drug use. Under the VOCAA, as already noted, any specific expenses claimed need to have been incurred as a 'direct result' of the act of violence. Here, then, the specific legal question before the court was: but for the act of violence, would the expenses have been incurred? In order to resolve this question, the court considered how to account for the applicant's past drug use and addiction. How does the applicant and/or his treating doctors understand the origins of his drug use and subsequent addiction? What conclusions can be drawn from the available evidence about the causes of each? Moreover, what is the relationship between his addiction and substitution treatment? What are the origins of his hepatitis $\mathrm{C}$ and dental damage? Interestingly, deliberations under both section 54 and section 8 of the Act lead the court into fraught and complex territory, insofar as it involves analysis of the nature and origins of addiction and the ontology of the addict. In the next section we consider how the court enacts each of these 'problems'. 


\section{THE ORIGINS OF ADDICTION}

There are multiple theories about what addiction 'is' and how it 'works', why some people develop an addiction and how addiction should be treated (West 2001, 2006a, 2006b, 2013). As an extension of this, there is little consistency among policymakers, service providers and other key stakeholders about the key concepts of addiction, including questions around the capacity or ‘volition’ of the addict (Moore and Fraser 2013; West 2013). In short, policies and services make different problems of addiction, enacting as they do forms of agency for 'addicts'. Likewise, courts enact specific concepts of causation, volition and responsibility in addiction, and these practices have potentially serious implications for the individuals concerned. In the judgments we analysed for this research, it was not always apparent which problem of addiction was being deployed. Sometimes the language of addiction was used without reference to how the court established that an addiction was present, with the exception of one case (Rajah) where a specific reference to a diagnosis of 'substance dependence' under the fourth edition of the Diagnostic and Statistical Manual was included. This is not to say that there was no evidence for establishing the presence of an addiction in the remaining cases surveyed, simply that the evidence was not explained in the judgments themselves.

The case of $J M$, noted earlier, illustrates how the 'origins' and ontology of the addict are constituted - how, that is, particular problems of addiction come to be made in law - and illuminates the important role assumptions and claims about the 'properties' and 'effects' of drugs play in this process. In examining whether the costs of methadone, hepatitis $\mathrm{C}$ and dental treatment were compensable under the Act, the court considered how the applicant starting using drugs, what kinds of drugs he used, and how his subsequent dependence upon them developed. Implicit in the judge's reasoning was that there is a clear distinction between 
different kinds of substances - a division between what are sometimes called 'softer' and 'harder' drugs - and that these substances can be located on a (stable) continuum, where some drugs are inherently more dangerous, risky and problematic than others. Also implicit in the judge's reasoning is that the use of drugs at the 'harder' end of the continuum is a basic form of pathology that requires (psychological or scientific) explanation. According to the presiding judge in $J M$, individuals who struggle with drugs often begin with alcohol or cannabis, and progress to more ‘destructive and pernicious’ drugs, such as heroin. Similar claims were made in other cases, where judges found that individual users typically 'graduated' to harder drugs (e.g. Tatarskyj). In JM's case, the judge explained the applicant's drug use and subsequent addiction as a consequence of past trauma. In reaching this conclusion, considerable emphasis was placed upon the applicant's family and background, including the fact that he was one of seven children. In a crucial passage on heroin addiction and causation, the judge said:

None of the [other family members] are substance abusers. It appears to be a 'normal' family ... In short, although it is never possible to say with certainty what causes a young person to abuse drugs or alcohol, the evidence in this case satisfies me that the heroin abuse would probably not have occurred but for the sexual abuse ... and I think what the therapists were telling me is that graduation to that destructive and pernicious drug is often connected with deep-seated psychological problems which the young person involved is endeavouring to escape.

The language used here is significant insofar as the judge determined that JM's heroin use occurred because of the childhood sexual assault. In this way, a sufficient nexus between his drug use, subsequent 'addiction' and the act of violence was established. The court therefore performs $J M$ 's drug use and addiction as a pathology for which the applicant bears no responsibility. If not an injury caused by the act of violence itself (a question not specifically 
addressed in the decision), heroin use and addiction emerged - at the very least - as an 'effect' of trauma. The apparent 'normality' of the applicant's family unit was critical to each aspect of the judgment. The combined effect of positioning the applicant as an anomaly in his family unit and in enacting certain forms of drug use (in terms of both the kind of drug taken and the individual's relationship with that drug) as inherently abnormal is to produce the applicant's behavior as both an irregularity and a pathology. Similarly, the judge considered the applicant's dental issues (multiple fillings and tooth extractions) and acquisition of hepatitis $\mathrm{C}$ to be causally related to the initial sexual assault against him. His comments on dental treatment are especially telling, constituting JM's dental issues as consequences of heroin addiction. In this way, the court performs the addict as devoid of responsibility for acts and omissions that are usually understood to be the fault of the addict:

Evidence before me is that heroin addicts are likely to neglect their general health, including their dental health, as well as their diet. The likelihood is, in my opinion, that the applicant would probably not have required so much dental treatment but for his heroin abuse. [The barrister for the tribunal] argued that such things are really too remote and should not be allowed. He argued that the causal connection is not sufficiently direct. In response, I gave the example of the victim of a violent assault whose wounds are sutured but who subsequently develops an infection at the site of the wound. Plainly the cost of treating the infection is every bit as much a part of the treatment of the original condition as the suturing. As I say, I accept that neglect of dental health and of general health is part and parcel of serious heroin addiction and in my opinion there is no logical reason to treat these claims differently. (our emphasis)

In this instance, the application for compensation was approved, and awards for methadone, dental and hepatitis C treatment approved. 
In contrast, Nguyen involved an application for compensation by an individual who had sustained multiple gunshot wounds. The offender was a criminal associate of Nguyen's, and both had been engaged in heroin dealing. When Nguyen was caught and charged with possession and trafficking in heroin, he agreed to turn police informant against the offender in order to mitigate any possible sentence. It appears, however, that the police officer dealing with the case was corrupt and that he subsequently advised the offender of Nguyen's role as informant. As a reprisal for assisting the police, Nguyen was shot by the offender multiple times. Although he survived, he required several operations and spent almost two months in hospital. His application for compensation was refused at first instance based on his criminal history. The appeals court focused on two issues: first, whether the application should be precluded under the 'character' provision and secondly, whether, in the event his application could proceed, certain medical expenses should be approved. The specific issue in question was whether Nguyen should be entitled to be compensated for the costs of methadone that were incurred when the hospital administered it 'to treat both his opioid dependence and analgesic needs'. Unlike $J M$, there was nothing to indicate how or why the applicant had started using heroin, although the court found that 'the purpose of his heroin dealing was to support his habit'. In the absence of such an explanation, the court examined his role as an informant, concluding that his cooperation with police was sufficient to allow his application to proceed. His methadone treatment was not approved, however. A few factors appeared crucial to this outcome. First, the judge seemed to take issue with the applicant's credibility, explaining that:

He told me he had not used heroin for several months prior to the shooting. Whether this is true cannot be confirmed. It is a matter of notoriety that heroin addicts will at any given time assert that they are not taking heroin. 
He then suggested that 'even if the applicant had not needed the methadone for analgesia, he would probably have needed it to stabilise his opiate dependence'. It seems to us that there are at least three points of note here. The first is that as Nguyen's drug use predated the act of violence in question, there could be no possibility that his addiction was a 'direct result' of the shooting, unlike $J M$. The judge made no reference to that fact, nor to the 'but for' test examined in $J M$. Given that the evidence was that methadone was needed for both his opiate dependence and pain relief, it seems curious that it was not approved at least on the second ground (in the sense that but for the shooting, the pain relief would not have been needed). In this sense, the judge appears to be more concerned with methadone's role as a form of treatment for drug dependence than its function as a painkiller (see Keane 2013). Also, there is no account which configures Nguyen's drug use as an 'effect' or 'consequence' of previous trauma or abuse. Although we cannot be sure, we would tentatively suggest that the absence of an exonerating narrative may have played against him. As well, the judge doubted the authenticity of Nyugen's assertions about his past drug use, based on an assumption that heroin addicts have a tendency to be dishonest. This is a common trope in relation to people who use illicit drugs (Fraser and valentine 2008; Sedgwick 1993). Although we accept that people who use heroin may sometimes actively conceal their use, the judge seems to foreclose alternative possibilities, including the prospect that Nguyen is telling the truth, or that if he is concealing his drug use he may be doing so for other reasons, including a fear that disclosure will see him punished. In this way, Nguyen’s case reinforces the importance of pre-existing formulations of addiction in shaping outcomes for victims, including, especially, assumptions about the subjectivity and reliability of evidence offered by people who use drugs and the properties and 'effects' of drugs, including opioid pharmacotherapy.

In the case of Rajah, the applicant had experienced severe sexual abuse as a child, as well as violence, coercion and threats within her family home. The applicant also had a 
criminal history. Together with her addiction, that criminal history was considered relevant under section 54 of the Act. At first instance, her application for compensation was dismissed, so the applicant appealed. Psychological evidence before the court ${ }^{\mathrm{vi}}$ framed Rajah's drug use as an 'outcome of the childhood abuse', and a way of 'dealing' with and 'avoiding' her traumatic past. Drawing upon evidence from the applicant’s forensic psychologist, the court concluded that her addiction to illicit drugs was an 'injury' in and of itself: an 'effect', that is, of the violence to which she had been subjected. Her criminal activities were also found to be 'largely drug and alcohol related' and, in that respect, 'to be consequences of the injury the applicant sustained'. As in JM's case, the applicant was constituted as both suffering from an affliction and devoid of responsibility for her own actions, including her drug use and addiction and her criminal activities. A similar finding was made in Hay, where the applicant's criminal history was said to be a 'consequence' of addictions. Importantly, these findings appear to be at odds with approaches under the criminal law, where both Rajah and Hay were considered legally responsible for their criminal conduct and sustained multiple criminal convictions. This is just one example of the way that crimes compensation produces its own problem of addiction and unique version of agency in relation to addiction, a version that appears to emerge via a constellation of factors, including the remedial and beneficial aims and objectives of the legislative scheme itself (in the sense that courts might be motivated to produce more generous accounts of drug use, addiction and criminal activity). In all three examples, the origins of both drug use and addiction were located outside the individual body and in the social one: a seemingly less stigmatising and more generous approach to drug use and addiction - an important matter to which we will return. Crucially, however, the case law is not always consistent in this respect. In Tatarskyj, the judge suggested that addiction had 'fuelled' the applicant's criminal history but that it did 'not in any way minimise the severity' of his criminal record. The 
'origins' of his addiction were not explored in the written judgment, however, for reasons that remain unclear. These examples confirm that the crimes compensation case law is both inconsistent and uneven in its approach to addiction, especially where questions about volition, responsibility and causation are concerned. It appears, however, that where courts can locate evidence in mitigation of the addict's behaviour, awards of compensation might still be made.

\section{OTHER MITIGATING CIRCUMSTANCES}

A significant feature of the crimes compensation case law is the tendency of courts to emphasise aspects of the applicant victim's conduct and/or personal life - seemingly in mitigation of their drug use, addiction and criminal activity, and as a means of explaining how an award of compensation is justified in spite of these factors. These comments appear in the form of obiter dicta. This is a legal term referring to observations made within a judgment that help explain how a conclusion is reached. Although such comments are not ordinarily binding in future cases in and of themselves, they may be persuasive or influential in subsequent cases where similar questions are in issue. In Hassell, for example, the judge concluded that:

Although the applicant is a recovering drug addict who has associated with other addicts and/or traffickers this is not sufficient to deny him compensation particularly given his personal circumstances. He came across as being committed to his wife and family, and demonstrated remorse for his past conduct. (our emphasis)

Hassell's 'personal circumstances' were 'particularly' important in the decision to grant him compensation, in spite of his drug use, addiction and associations. In emphasising certain aspects of the applicant's character and personal life, including the fact that he was both 'committed' to his family and 'remorseful', the judge produces addiction as something for 
which the applicant still needs to account. It is vital, in other words, for the applicant to show that she or he is now exhibiting behaviors typically associated with 'responsible citizenship', however that is constituted (Procacci 2004; Nyers 2004). In Hay, for example, the court referred to the applicant's 'genuine effort to reform and [that] since marrying and having two children, he has endeavoured to find useful employment and demonstrated a keen desire to support his family'. Similarly, in Rajah's case, weight was given to the fact that the applicant was now making a 'genuine effort to overcome her drug and alcohol dependency problems and ... making an effort to be a responsible parent'. These examples suggest that the need to account for oneself as a responsible, rational and contrite subject appears to be important even in those cases where addiction is constituted as an injury, effect or consequence of trauma for which the addict bears no responsibility. In this sense, crimes compensation courts produce a contradictory set of messages about addiction and volition, raising questions about precisely how addicts might claim citizenship in a context where they are positioned as simultaneously exempt from responsibility and accountable for their actions (XXXX 2010a, 2010b). This raises serious questions about how people positioned as 'addicts' should navigate the complex and contradictory web of ideas and values produced in crimes compensation, and the inconsistent ways their status, agency and capacities will be problematised. It is also unclear what might happen to victims who are not able to produce such accounts of themselves, or whose actions and subjectivities do not accord with judicial formulations of responsible citizenship.

\section{CONCLUSION}

In this paper we have explored the novel question of how crimes compensation courts produce the 'problem' of drug use and/or addiction in relation to applications for victims of crime compensation. Our analysis shows that 'addicts' who enter the legal system as victims 
of crime are subjected to considerable scrutiny and criticism, with their motives, relationships and trustworthiness given close attention. It appears that a great deal of work must be done to in order for people who consume drugs to achieve the legal rights and benefits afforded to other Australian citizens who are subjected to acts of violence. We argue that people who consume drugs/are constituted as 'addicts' face considerable obstacles in order to access victims of crime compensation, especially through interpretations of the 'character' provision which permits courts to examine any aspect of the applicant's behaviour, past or attitude in deciding whether or not compensation is justified. (Unfortunately it is not possible to authoritatively establish the relative burden faced by 'addicts' compared to those individuals whose applications for crimes compensation meet challenge for other reasons under the character provision, as the court does not publish all of its decisions). Although there may be several strategic benefits associated with positioning oneself as an 'addict' once an individual's drug consumption becomes known in crimes compensation proceedings, our analysis finds an uneven and at times contradictory set of approaches to the relevance and 'origins' of drug use and addiction in crimes compensation case law. At times, addiction is found to emanate from the individual body and to represent a relevant instance of poor character that might threaten a victim's right to be compensated for the commission of a violent crime against them. At other times, addiction is constituted as stemming from the social body, positioned as an 'effect' of social practices, arrangements and relationships (including sexual abuse or sexual assault in childhood). In this sense, addiction is performed as a social problem that coheres within an individual body and manifests as a seemingly private phenomenon (albeit with broader social 'effects', including subsequent criminal activity). In so doing, crimes compensation courts simultaneously perform addiction as something for which the wider community bears responsibility. 
This would no doubt be viewed by some as a largely progressive and more generous narrative, one that locates blame outside the individual 'addict'. Unfortunately, however, a closer examination of the extant case law shows that attributions of addiction-causation to the social body almost always depend upon a simultaneous configuration of drug use and addiction as inherently abnormal, dysfunctional and pathological. On occasion (as in the case of Hassell), these processes of pathologisation extend even to an applicant's relationships: where a victim's friendships with other 'addicts' come to be constituted as 'poor choices' and sinister 'associations' for which the applicant must account. Ironically, of course, context is key: if Hassell had been associating with other addicts at a meeting for Alcoholics or Narcotics Anonymous, the relevance and nature of those associations would probably have been understood very differently. Is it appropriate that an individual who has been raped, assaulted or sexually abused be expected to apologise for their relationships in such a way? And what are the effects of this on the individual victim concerned? As a result of these challenges, addicts (and their lawyers) may be compelled to produce an exculpatory account of their own drug use, addiction and relationships that accords with the court's conception of these as pathological. This would be an ironic result in at least one important sense. Here, legislation which has the explicit aim of remedying loss and benefiting victims may have the unintended effect of generating its own set of losses and disadvantages for some of its intended beneficiaries. In particular, applicants are constituted as suffering from another kind of sickness, a designation that carries with it considerable potential for stigma (e.g. Brook and Stringer 2005). In this way, we argue the crimes compensation system has the capacity to both generate and exacerbate harms by producing and reproducing disordered, marginalised and devalued versions of subjecthood (in the form of the 'sick'/'addicted' victim). In this sense, as we noted at the outset, our analysis offers a critical challenge to the 'realist' approach to drug 'problems', which suggests that drugs have certain (negative) effects, and 
that the origins of drug-related harms lie within the chemical properties of drugs themselves (see Moore and Fraser 2013). Instead, our research finds that harms may originate from and be aggravated through legal processes themselves; this is a deeply concerning phenomenon.

As we have argued elsewhere, people constituted as ‘addicts' are a very diverse population of individuals who experience their drug use and agency in a range of ways (XXXX 2010a, 2010b; XXXX 2011). This diversity is potentially at odds with the demands of the court system, especially the apparent need to produce an explanation for drug use and addiction based in past trauma or tragedy. In this respect, these legal processes operate to foreclose alternative possibilities regarding drug use, including the possibility that individuals who use drugs experience them as pleasurable. They also foreclose alternative explanations that see drug use as something other than inherently problematic or connected to past trauma. Indeed, there is a genuine possibility that individuals who consume drugs would be best advised to downplay or dismiss the pleasurable and/or non-pathological aspects of their drug use in favour of a more complex and cautious narrative in which they position themselves as acting out of their troubled past. As this appears to provide the greatest chance of success in obtaining victims of crime compensation, such processes also raise questions about how drug use/addiction might be constituted in the absence of trauma, past abuse, or neglect, or whether judicial processes allow space for alternative accounts of use and addiction. It is possible that in the absence of either a willingness or ability to produce a sufficiently compelling narrative to justify illicit drug use and/or addiction, applications for compensation will be refused. This would be an unfortunate outcome given that, as we noted earlier, the scheme is supposed to be beneficial rather than punitive.

It is important to note here that the enactment of drug use and addiction as 'effects' of trauma appears to reflect a broader shift towards the concept of trauma. According to Fassin and Rechtman (2009), whose work focused on the rather different topic of empire and 
trauma, the notion of trauma and its companion concept, the 'psychic wound', are relatively new to psychiatry. Fassin and Rechtman trace the way, for instance, soldiers previously diagnosed as suffering from 'shell shock' (a once-maligned condition believed to be evidence of malingering, neurosis, or individual weakness) came to be repositioned as suffering from the psychiatric condition of Post-Traumatic Stress Disorder (PTSD). With their symptoms reconstituted as effects of trauma rather than of a personal or moral failing, soldiers acquired a newfound validity as 'victims'. In a similar sense, it is possible that what we are seeing in some of these cases may also be an effect of the enactment of trauma as a social (and legal) category. Importantly, however, the language of trauma and victimhood is only extended to certain practices, behaviours and subject positions already considered to represent pathologies. These mutually co-constitutive entanglements (of trauma, victimhood, addiction and the law) are, we suggest, important phenomena, and they demand a more thorough exploration in future research.

In analyses regarding the nature and function of drug courts that have an ostensible focus on rehabilitating rather than punishing 'addicts', it has often been argued that the criminal law still operates to stigmatise, marginalise and punish addicts for their putative 'illness'. This research shows that a similar process is in operation even among legislative schemes with an explicitly remedial rationale, and that this is a phenomenon researchers and legal practitioners rarely acknowledge and must better understand. As we noted earlier, these approaches also raise important questions for policymakers and governments, especially as law, policy and service provision are often entangled, mutually interdependent and coconstitutive. Insofar as legal processes like the ones we have highlighted here produce certain accounts of drug use and 'addiction', they have the potential to place people into particular relationships with the state (as variously sick, traumatised, worthy of support, or culpable in their 'addiction'). Importantly, as we noted earlier, these narrow judicial formulations also 
have a tendency to become fixed via the legal doctrine of precedent: a legal principle that requires judges to apply judicial reasoning from past cases to future cases with similar facts. In this sense, narrow and potentially stigmatising accounts of drug use, addiction and addicted subjectivity may become entrenched through - and compounded by - judicial processes. Questions therefore need to be asked about the relationship between law and policy, including the potential for legal and policy responses to work together in compounding the stigmatisation and marginalisation of people who use drugs and drug 'addicts'. In concluding, we return to Bacchi's six questions, in particular the last one, which asks us to consider how the problematisations we have identified can be questioned, disrupted and replaced. This article has taken a range of steps to question the problematisations of addiction presently being enacted in victims of crime compensation case law, and we hope that by pointing to them and their effects the paper contributes to their disruption. As for replacing them, much research remains to be done in legal contexts. It is not yet clear how people constituted via legal processes such as these experience their problematisation as addicts and the effects of this process. Insights on these issues are indispensable for the development of alternatives. We plan to investigate these issues in future research.

\section{References}

Bacchi, C. (2012). Why study Problematizations? Making Politics Visible. Open Journal of Political Science, Vol. 2, No. 1, 1-8.

Bacchi, C. (2009). Analysing policy: What is the problem represented to be? Sydney: Pearson.

Barad, K. (2007). Meeting the Universe Halfway: Quantum Physics and the Entanglement of Matter and Meaning. Durham: Duke University Press. 
Beichner, D. and Spohn, C. (2012). Modeling the Effects of Victim Behavior and Moral Character on Prosecutors’ Charging Decisions in Sexual Assault Cases. Violence and Victims, 21: 3-24.

Brook, H. and Stringer, R. (2005). Users, using, used: A beginner’s guide to deconstructing drugs discourse. International Journal of Drug Policy. 16(5), 316-325.

Burns, S. and Peyrot, M. (2003). Tough love: Nurturing and coercing responsibility and recovery in California drug courts. Social Problems, 50(3): 416-438.

Butler, J. (1990). Gender Trouble: Feminism and the subversion of identity. New York: Routledge.

Butler, J. (1993). Bodies that Matter: On the discursive limits of 'sex'. New York: Routledge. Butler, J. (2010). Performative Agency. Journal of Cultural Economy. Vol. 3, No. 2, 147161.

Clancey, G. and Howard, J. (2006). Diversion and criminal justice drug treatment:

Mechanism of emancipation or social control? Drug and Alcohol Review, 25: 377-385.

Deacon, R. (2000). Theory as practice: Foucault's concept of problematization. Telos, 118, 127-142.

Deleuze, G. (1994). Difference and Repetition. London: Athlone Press.

Demant, J. (2013). Affected in the nightclub. A case study of regular clubbers’ conflictual practices in nightclubs. International Journal of Drug Policy, Vol. 24, No. 3, 196-202. Duff, C. (2013). The social life of drugs. International Journal of Drug Policy, Vol. 24, No. 3, $167-172$.

Duff, C. (2012). Book review essay: After methods, after subjects. Contemporary Drug Problems, Vol. 39, No. 2. 
Dwyer, R. and Moore, D. (2013). Enacting multiple methamphetamines: The ontological politics of public discourse and consumer accounts of a drug and its effects. International Journal of Drug Policy, Vol. 24, No. 3, 203-211.

Fassin, D. and Rechtman, R. (2009). The Empire of Trauma: An Inquiry into the Condition of Victimhood. Princeton: Princeton University Press.

Fitzgerald, J. (2008). Drug diversion: An intersection between law enforcement and public health approaches to the control of illicit drug use. In D. Moore \& P. Dietze (Eds.) Drugs and Public Health. Oxford and London: Oxford University Press, 103-113.

Foucault, M. (1977). Language, counter-memory, practice: selected essays and interviews. In D. F. Bouchard (Ed.). Ithaca, New York: Cornell University Press.

Foucault, M. (1985). Discourse and truth: The problematization of parrhesia. In J. Pearson (Ed.), Evanston, IL: Northwestern University.

Foucault, M. (1988). The Concern for Truth. In L. D. Kritzman (Ed.) Michel Foucault: Politics, philosophy, culture. Interviews and other writings, 1977-1984. Trans. A Sheridan. New York: Routledge, 255-267.

Fraser, S. and Moore, D. (Eds.) (2011). The Drug Effect: Health, Crime and Society. Melbourne: Cambridge University Press.

Fraser, S. and valentine, k. (2008). Substance and substitution: Methadone subjects in liberal societies. Basingstoke: Palgrave.

Freckleton, I. (2004). Compensation for victims of crime. In H. Kaptein and M. Malsch (Eds.) Crime, victims and justice: Essays on principles and practice. Aldershot: Ashgate. Gowan, T. and Whetstone, S. (2012). Making the criminal addict: Subjectivity and social control in a strong-arm rehab. Punishment and Society, 14(1): 69-93. 
Grubb, A. and Turner, E. (2012). Attribution of blame in rape cases: A review of the impact of rape myth acceptance, gender role conformity and substance use on victim blaming. Aggression and Violent Behavior, 17(5), 443-452.

Hammersley, R. (2008). Drugs and Crime. Cambridge: Polity Press.

Keane, H. (2013). Categorising methadone: Addiction and analgesia. International Journal of Drug Policy, Published online on 12 June 2013. (http://www.ijdp.org/article/S09553959(13)00081-9/abstract)

Keane, H. (2002). What's Wrong with Addiction? Melbourne: Melbourne University Press (an imprint of Melbourne University Publishing).

Koss, M. (2000). Blame, shame, and community: Justice responses to violence against women. American Psychologist, Vol. 55, No. 11, 1332-1343.

Lancaster, K. and Ritter, A. (2013). Examining the construction and representation of drugs as a policy problem in Australia’s National Drug Strategy documents 1985-2010.

International Journal of Drug Policy, Published online 12 August 2013. (http://www.ijdp.org/article/S0955-3959(13)00117-5/abstract)

Lancaster, K., Hughes, C., Chalmers, J. and Ritter, A. (2012). More than problem-solving: Critical reflections on the 'problematisation of alcohol-related violence in Kings Cross. Drug and Alcohol Review, Vol. 31, 925-927.

Law, J. and Mol, A. (2002). (Eds.) Complexities: Social Studies of Knowledge Practices. Durham: Duke University Press.

Licoppe, C. (2010). The 'performative turn' in Science and Technology Studies: Towards a linguistic anthropology of ‘technology in action’. Journal of Cultural Economy. Vol. 3, No. 2, $181-188$. 
Lyons, T. (2013). Simultaneously treatable and punishable: Implications of the production of addicted subjects in a drug treatment court. Addiction Research and Theory, Published online on October 3, 2013. (doi:10.3109/16066359.2013.838227)

MacKinnon, C. (2005). Women’s lives, men’s laws. Cambridge: Harvard University Press. MacKinnon, C. (1987). Feminism unmodified: Discourses on life and law. Cambridge: Harvard University Press.

Moore, D. and Fraser, S. (2013). Producing the 'problem' of addiction in drug treatment. Qualitative Health Research, 23(7), 916 - 923.

Murphy, J. (2012). The continuing expansion of drug courts: Is that all there is? Deviant Behavior, 33, 582-588.

Murphy, J. (2011). Drug court as both a legal and medical authority. Deviant Behavior, 32: 257-291.

Nyers, P. (2004). What’s left of citizenship? Citizenship Studies, 8 (3), 203-215.

Procacci, G. (2004). Governmentality and citizenship. In: K. Nash and A. Scott, eds. The Blackwell companion to political sociology. Oxford: Blackwell.

Seddon, T. (2011). Court-ordered treatment, neoliberalism and Homo economicus. In S. Fraser and D. Moore (Eds.) (2011). The Drug Effect: Health, Crime and Society. Melbourne: Cambridge University Press, 155-170.

Seddon, T. (2011). Explaining the drug-crime link: Theoretical, policy and research issues. Journal of Social Policy, 29(1), 95-107.

Sedgwick, E. (1993). ‘Epidemics of the will’ in Sedgwick, E. (ed.) Tendencies Routledge: London, pp. 129-140.

Stevens, A. (2007). When Two Dark Figures Collide: Evidence and Discourse on Drugrelated Crime. Critical Social Policy, 27(1), 77-99. 
Tyson, D. (2013). Sex, Culpability and the Defence of Provocation. London: RoutledgeCavendish.

Vrecko, S. (2009). Therapeutic Justice in Drug Courts: Crime, Punishment and Societies of Control, Science as Culture, Vol. 18, No. 2, 217-232.

West, R. (2001). Theories of Addiction. Addiction, 96, 3-13.

West. R. (2006a). Theory of Addiction, Blackwell: Oxford.

West, R. (2006b). Towards a comprehensive theory of addiction. Drugs and Alcohol Today, Vol. 6, Issue 1, March, 28-32.

West, R. (2013). Models of Addiction. European Monitoring Centre for Drugs and Drug Addiction Insights: Lisbon.

XXXX (2011).

XXXX (2010a).

XXXX (2010b). 
${ }^{\mathrm{i}}$ When an offender is convicted, there is also provision under the Sentencing Act for the court to make an award of compensation to the victim as part of the process of sentencing the offender.

ii The decision-makers in the cases that we consider have a variety of titles including 'member' and 'judge'. These titles denote different levels of appointment in the Victorian judicial system. For ease of reference, we will refer to all decision-makers using the generic title of 'judge', in order to avoid confusion.

${ }^{\text {iii }}$ We considered it important to confine our analysis to one jurisdiction for a range of reasons. Most importantly, exploring how addiction surfaces in victims of crime cases within one jurisdiction across time enabled us to explore how and in what ways understandings of addiction and concepts such as volition figure in the case law, and any tensions, coherences or in/consistencies in approach. As an extension of this, considering how these issues are conceptualised within one jurisdiction allows us to consider how - if at all - earlier cases figure as a precedent for later decisions dealing with addiction. Also, as we noted earlier, Victoria is an interesting jurisdiction insofar as it is mandatory to consider the applicant victim's character, but there is no legislative direction as to how the provision should be interpreted.

${ }^{\text {iv }}$ We also excluded other cases where reference to dependence in the case law was not relevant to drug or alcohol use (e.g. where the applicant had become financially dependent on another person). As the AUSTLII search engine deals only with reported decisions, it is possible that other cases where questions pertaining to addiction have been raised have been missed in this analysis. Our analysis does not purport, therefore, to be a comprehensive overview of all victims of crime case law in the state of Victoria where addiction has 
featured. The cases that we examine are: Nguyen $v$ VOCAT [2001] VCAT 2028; JM v VOCAT [2002] VCAT 496; Rajah v VOCAT [2002] VCAT 1422; Hay v VOCAT [2002] VCAT 45; Hassell v Victims of Crime Assistance Tribunal (General) [2011] VCAT 2106; Tatarskyj v Victims of Crime Assistance Tribunal (General) [2011] VCAT 1480; and Larson v Victims of Crime Assistance Tribunal (General) [2012] VCAT 1162.

${ }^{\mathrm{v}}$ Unfortunately the written reasons for judgment contain little insight into how addiction might be relevant to the question of delay, including whether and how addiction impacted upon the applicant's capacity to bring the application any earlier. The case of Hay only briefly addresses this issue. In that case, the presiding judge allowed the application although it was out of time and listed the applicant's 'abuse’ of drugs and alcohol as both a child and an adult as one of several 'acceptable explanations' for the delay. In the other two cases, the application was allowed to proceed despite being out of time, although multiple other factors may have also been at play. This suggests that courts may see 'addiction' as having an effect on an applicant's capacity, or their capacity to deal with complex and traumatic events, although there is unfortunately insufficient detail in the judgments we consulted to explore these issues further.

${ }^{v i}$ This expert psychological evidence is not publicly accessible. We aim to explore the role of expert evidence and psychological framings of drug use and 'addiction' in the law in future research. 